\title{
Rabbit as a reproductive model for human health
}

\author{
Bernd Fischer, Pascale Chavatte-Palmer ${ }^{1,2,3}$, Christoph Viebahn ${ }^{4}$, Anne Navarrete Santos and \\ Veronique Duranthon ${ }^{1,2}$ \\ Department of Anatomy and Cell Biology, Martin Luther University Faculty of Medicine, Grosse Steinstrasse 52, \\ D-06097 Halle (Saale), Germany, ${ }^{1}$ INRA, UMR1198 Biologie du Développement et Reproduction, F-78350 \\ Jouy-en-Josas, France, ${ }^{2}$ ENVA, F-94700 Maisons Alfort, France, ${ }^{3}$ PremUp Foundation, 4 av. de l'Observatoire, \\ F-75006 Paris, France and ${ }^{4}$ Department of Anatomy and Embryology, Georg-August-Universität, D-37075 \\ Göttingen, Germany
}

Correspondence should be addressed to B Fischer; Email: bernd.fischer@medizin.uni-halle.de

\begin{abstract}
The renaissance of the laboratory rabbit as a reproductive model for human health is closely related to the growing evidence of periconceptional metabolic programming and its determining effects on offspring and adult health. Advantages of rabbit reproduction are the exact timing of fertilization and pregnancy stages, high cell numbers and yield in blastocysts, relatively late implantation at a time when gastrulation is already proceeding, detailed morphologic and molecular knowledge on gastrulation stages, and a hemochorial placenta structured similarly to the human placenta. To understand, for example, the mechanisms of periconceptional programming and its effects on metabolic health in adulthood, these advantages help to elucidate even subtle changes in metabolism and development during the pre- and peri-implantation period and during gastrulation in individual embryos. Gastrulation represents a central turning point in ontogenesis in which a limited number of cells program the development of the three germ layers and, hence, the embryo proper. Newly developed transgenic and molecular tools offer promising chances for further scientific progress to be attained with this reproductive model species.

Reproduction (2012) 144 1-10
\end{abstract}

\section{Introduction}

After mice (59.3\%) and rats $(17.7 \%)$, the laboratory rabbit is the third most often used experimental mammal (2.78\%) within the EU (EU report 2010: http://eur-lex. europa.eu/LexUriServ/LexUriServ.do? uri $=$ COM:2010: 0511:REV1:EN:PDF (http://www.ncbi.nlm.nih.gov/projects/genome/guide/rabbit). The vast majority of experimental rabbits are used for 'other human diseases', i.e. not for categories like cardiovascular diseases, nervous and mental disorders, cancer or animal diseases. In toxicological testing, the rabbit is often the compulsory second laboratory species besides mice or rats, and the preferred one in the testing of chemicals regarding acute dermal irritation (OECD Guideline Test No. 404). The European rabbit (Oryctolagus cuniculus) belongs taxonomically to the mammalian order lagomorpha and - together with hares - to the family Leporidae. The rabbit-primate phylogenetic distance is the same as the rodent-primate one. However, because rodent sequences evolved more rapidly, rabbit gene sequences are more similar to human sequences than rodent ones (Graur et al. 1996).

Historically, the rabbit was a 'classical' species in the first decades of embryology and reproductive biology, starting from the late 19th century. Hensen's (or the 'primitive') node, the 'organizer' of gastrulation and, as a result, of the main body axes, was first described in the rabbit by Hensen in 1876 (Viebahn 2001); and Brachet (1913) described the in vitro development of rabbit 'blastodermic vesicles'. The teratogenic effects of thalidomide were found in the laboratory rabbit but not in rodents (Somers 1962, Hay 1964, Schumacher et al. 1968, Gottschewki \& Zimmermann 1973, Lenz 1988). Paradigmatic research in reproductive biology using the rabbit as a model animal is associated with a number of well-known pioneers of reproductive biology, such as C E Adams (sperm and oocyte transport, prenatal mortality), C R Austin (capacitation of spermatozoa, oocyte maturation and fertilization), R A Beatty (genetics of gametes), J M Bedford (sperm morphology), G Pincus (fertilization in the rabbit; 1932), E S E Hafez (fertilizability of ova, embryo survival), D W Bishop (oviduct physiology), H M Beier (uteroglobin, endocrine regulation of uterine secretion), M C Chang (experimental embryology and endocrinology), C Lutwak-Mann (biochemical analysis of blastocyst and uterine fluid), C Thibault (IVF), R R Maurer and M Kane (embryo in vitro culture), J C Daniel Jr (preimplantation embryo 
development in vivo and in vitro, uterine secretions), H-W Denker (trophoblast-endometrial interactions at implantation), A C Enders (ultrastructure of implantation and placentation), F Seidel (developmental competence of isolated blastomeres), G H M Gottschewski (normo- and teratogenesis in the rabbit), A Jost (sexual differentiation), and M F Hay and $\mathrm{H}$ Tuchmann-Duplessis (teratogenesis) (non-exhaustive list of names and disciplines). In the last 30 years, however, isolation of embryonic stem (ES) cells, allowing the easy generation of knockout phenotypes, and an abundance of molecular data and markers have promoted the mouse as the most often used laboratory animal in reproductive and, particularly, developmental biology. Nevertheless, there are numerous advantages that make the rabbit a highly suitable animal model for studies in reproduction.

\section{Ovulation and preimplantation embryo development}

Female rabbits have a uterus duplex, i.e. two separated functional uteri and cervices, with a vagina simplex. The uterus duplex allows the transfer of two embryo groups to the same recipient female. The native fertility of rabbits is high ( $>$ 8-9 embryos per female, depending on breed and strain) and can be increased by routinely employed hormonal treatments in order to reduce the number of donor rabbits (Fischer \& Meuser-Odenkirchen 1988, Ramin et al. 2010). Even in females suffering from metabolic diseases like diabetes mellitus, high blastocyst yields can be achieved by hormonal follicle stimulation (at day 6 post coitum (p.c.) 13.3 blastocysts in diabetic and 21.9 in control rabbits; Ramin et al. (2010)).

The size of the genital tract facilitated seminal landmark investigations on the endocrine and paracrine regulation of embryo-maternal interactions and uterine receptivity in early pregnancy and on hormone responsiveness of endometrial secretion, as highlighted by progesterone-regulated uteroglobin (Beier 1968, 2000). Recently, it was shown that the rabbit is a good model for Asherman's syndrome, or uterine synechia, defined as a partial or complete obliteration of the uterine cavity and/ or the cervical canal, and which can cause infertility and recurrent pregnancy losses (Fernandez $\mathrm{H}$, Krouf $\mathrm{M}$, Morel $\mathrm{O}, \mathrm{Ali} \mathrm{MH}$ \& Chavatte-Palmer $\mathrm{P}$, unpublished observations). So far, synechia, which are frequently observed after uterine curettage in women, had been reported in the mare only.

The rabbit belongs to the few species in which ovulation is induced by mating, resulting in an exactly defined pregnancy and embryonic age (hours or days p.c.). The rabbit has a short reproductive cycle. Pregnancy lasts for 31 days, with female sexual maturity occurring, depending on strains, at about 4-5 months of age. Without mating/insemination, pseudopregnancy can be triggered by hormonal treatment (LH, hCG), resulting in functional corpora lutea for 12 days. Fertilization and implantation can be achieved from day 15 after unsuccessful mating or pseudopregnancy (Fischer et al. 1986).

Fertilization, cleavage and prenatal mortality have been investigated extensively by C E Adams (Adams 1960a, 1960b, 1962, 1982). Fertilization occurs at $\sim 10$ h p.c. (Harper 1961), with the second polar body being visible at about $14 \mathrm{~h}$ p.c. Until the 16-cell stage, blastomeres divide every 7 to 8 h. Morulae ( $\sim 60$ h p.c.) have cell numbers $>32$. Compaction, coinciding with the establishment of the first cellular junctions, occurs at $\sim 68 \mathrm{~h}$ p.c. and blastocyst formation (appearance of blastocyst cavity and differentiation of embryoblast (ICM) and trophoblast) at $72 \mathrm{~h}$ p.c. The size of day 4 blastocysts is $\sim 1 \mathrm{~mm}$ and expands to a diameter of 2 to $6 \mathrm{~mm}$ until implantation at day 6 and $18 \mathrm{~h}$ (Denker 1977). Measurements of cell numbers at day 5 differ between 1291 and 9536, and on day 6 between 80000 and 100000 (Fischer et al. 1986). Embryoblast cell numbers in the embryonic disc at day 6 p.c. are $\sim 2000$ in stage 1 blastocysts (Ramin et al. 2010) and 7000 in stage 2 (Thieme et al. 2012a). Shortly prior to implantation, the polar trophoblast covering the embryonic disc (Rauber trophoblast) is shed, exposing the embryoblast cells to the uterine luminal epithelium (Williams \& Biggers 1990, Tscheudschilsuren et al. 1999). The rabbit embryo enzymatically dissolves the zona pellucida during day 4 (Denker \& Gerdes 1979) and replaces it by the neozona during day 5 p.c. The peri-implantation blastocyst is covered by three extracellular coverings: the neozona, remnants of the mucoprotein layer deposited during tubal passage and uterine secretions (Denker 1977, Fischer et al. 1991).

The size of the expanded rabbit blastocyst (the largest spherical blastocyst in mammals) allows the collection of sufficient material for morphological and molecular analyses of individual blastocysts from single females. Diameter and developmental stage can be reliably analyzed and allow a firm evaluation of physiological parameters such as protein synthesis (Jung \& Fischer 1988), cellular transport (Biggers et al. 1988) or glucose uptake (Navarrete Santos et al. 2004b) in intact blastocysts and in separated embryoblast and trophoblast cells (Navarrete Santos et al. 2008, Thieme et al. 2012a).

\section{Molecular events during preimplantation embryo development}

Embryonic genome activation (EGA) in the rabbit spans several cell cycles, as in most mammals including humans but opposite to the mouse (Telford et al. 1990). Such interspecies differences are significant for EGA regulation, since each DNA replication offers specific opportunities for nucleo-cytoplasmic interactions involved in genome reprogramming. The rabbit genome is fully active from the 8 - to 16 -cell stage 
onward (Manes 1973, Pacheco-Trigon et al. 2002). Gene reprogramming during the preimplantation period of development has been partly described using a dedicated array (Leandri et al. 2009), providing a first representative description of gene reprogramming in this species. It is characterized by overlap between maternal and embryonic information. The degradation of maternal transcripts progresses through the entire cleavage period, with different kinetics for different genes. Embryonic transcripts also accumulate with different kinetics, with a significant proportion displaying a sharp and transient increase at EGA. Epigenetic events during this period are highly dynamic. The use of the rabbit embryo has brought new insights into the general mechanisms that affect gene expression and/or further development in mammals, i.e. pericentromeric heterochromatin organization, DNA methylation and $\mathrm{X}$ chromosome inactivation $(\mathrm{XCl})$.

The rabbit somatic structure of pericentromeric heterochromatin with pericentromeres that do not cluster into chromocenters is close to the human organization and different from the mouse (Andrey et al. 2010). In the embryo, the somatic-like organization of pericentromeric heterochromatin appears concomitantly to EGA (Yang, personal communication).

The quantitative study of DNA methylation dynamics has shown that, in the zygote, the methylation of the maternal pronucleus DNA remains constant due to the maintenance of methylase activity during the $S$ phase. Conversely, paternal DNA is first actively but partially demethylated before DNA replication, and subsequently remains constant during the $S$ phase when the maintenance methylase activity is active (Reis Silva et al. 2011). A passive DNA demethylation then occurs between the four- and 16-cell stage. In the blastocyst, as in most mammalian species, DNA methylation is higher in embryoblast cells than in trophoblast cells. These data demonstrate that both heterochromatin structure and DNA methylation levels are highly modified concomitantly with the onset of EGA. Because the kinetics of EGA in the rabbit is close to most mammalian embryos but different from the mouse, the rabbit embryo is now used as a pertinent model to analyze the environmental effects on these epigenetic changes. For example, in vitro development was shown to modify DNA demethylation dynamics in the paternal pronucleus and during cleavages (Reis Silva et al. 2012).

$\mathrm{XCl}$ in female mammals ensures dosage compensation for $X$-linked genes. Developmental regulation of this major epigenetic process had been analyzed in detail in the mouse where the maternal imprint of Xist, the noncoding transcript responsible for $X$ inactivation, results in the early inactivation (four- to eight-cell stage) of the paternal $X$ chromosome. This imprinted inactivation persists in the extraembryonic tissues while in the pluripotent embryoblast cells, paternal X chromosome reactivation precedes a random inactivation in each cell.
This situation was considered to be representative for the eutherian situation. The use of the rabbit embryo as an alternative model for in vivo developed embryos, however, evidenced a high diversity in the early regulation of $X$ inactivation among eutherians. In particular, both the early imprint of Xist and the reactivation of the previously inactivated $X$ chromosome in the pluripotent cells of the inner cell mass were shown to be mouse specific. It may be that the maternal imprint of Xist in mice evolved to avoid premature maternal $X$ inactivation in a species with very early EGA and $X i s t$ expression (Okamoto et al. 2011). In the rabbit embryo, Xist is expressed from both $X$ chromosomes and accumulates in the blastocyst on both $X$ chromosomes in a high proportion of cells. Xist expression becomes monoallelic only at the late blastocyst stage, first in the trophoblast, and then in the embryoblast. The functional consequence of Xist expression, i.e. repression of $X$-linked genes, seems to occur only at the blastocyst stage. Both the nonimprinted early expression of Xist and the delay in $\mathrm{X}$-linked genes inactivation are common to rabbit and human embryos when compared with the mouse (Okamoto et al. 2011).

\section{Gastrulation}

A central turning point in blastocyst differentiation and vertebrate ontogenesis is gastrulation. The body plan with regard to axis formation and the starting point for germ layer formation (ecto-, meso- and endoderm) is set. The anterior-posterior (cranio-caudal) body axis (with dorsal-ventral polarity) and, consequently, left-right axis in mammals is first and definitively fixed and the mesoderm emerges as the earliest germ layer to be identified.

The embryo proper of most gastrulation-stage mammals, including the human and rabbit, has the shape of a flat disc with two cell layers (epiblast and hypoblast; for review, see Viebahn (1999)). Gastrulation in the rabbit starts at day 6 p.c., i.e. at a stage that is easily accessible, as implantation has not yet started. Seven gastrulation stages have been identified so far (Fig. 1), using morphological and molecular methods (Viebahn et al. 1995, 2002, Schafer-Haas \& Viebahn 2000, Viebahn 2004) and the staging system developed by Hamburger \& Hamilton (1992) for the chick as a template to facilitate intra-amniote interspecific comparison. Implantation takes place at stage 4 . Stage 0 is a blastocyst with no apparent axial differentiation in the embryonic disc (e.g. at day 5.5 p.c.). The onset of gastrulation (stage 1 ), found at day 6.0 p.c., is characterized by a crescentlike dense area in the anterior part of the embryonic disc (anterior marginal crescent; Viebahn et al. (1995)), followed about $6 \mathrm{~h}$ later by a sickle-shaped elongation of reduced density at the posterior pole (posterior gastrula extension, PGE; stage 2; Viebahn et al. (2002)). Appearance of the primitive streak in the 

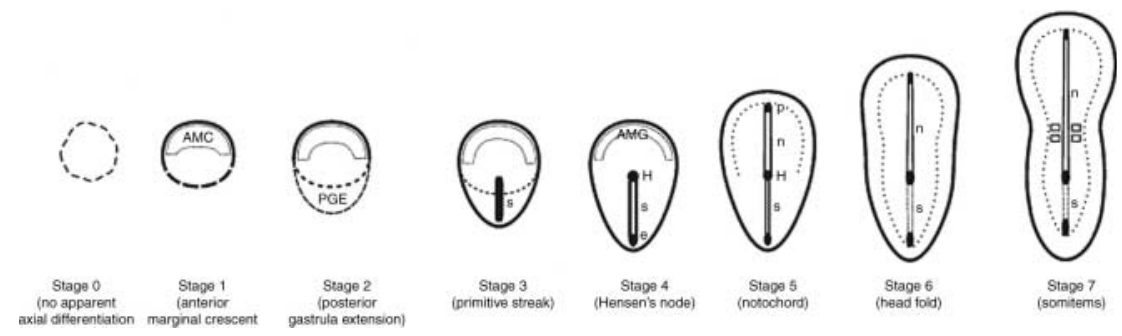

Figure 1 Schematic drawing of the gastrulation stages 0 to 7 in the rabbit. For details, see text.

midline of the PGE, generating the first mesoderm cells, defines stage 3 . The mesoderm is formed by epitheliomesenchymal transition of epiblast cells under the 'finetuning' influence of the hypoblast at stages 1 and 2 (Idkowiak et al. 2004). Movement, migration, and epithelio-mesenchymal transformation of epiblast cells, resulting in primitive streak formation, characterize stage 3 (Viebahn et al. 2002) until the primitive streak encompasses up to half of the longitudinal axis of the embryonic disc. The appearance of Hensen's node at the tip of the primitive streak characterizes stage 4 and coincides with the time when implantation starts. This classification finishes with stage 7 when the first somites become visible.

In principle, this series of stages is found in all mammals including rodents in which, however, the embryonic disc is forced into the complex shape of the so-called egg cylinder in which the anterior and posterior poles of the embryo come to lie in close proximity to each other and an additional (proximo-distal) body axis has to be taken into account (Beddington \& Robertson 1999). Results obtained on the epithelio-mesenchymal transition or on extraembryonic control of gastrulation in the mouse blastocyst are, therefore, difficult to extrapolate to other mammalian embryos including the human. Early cell-lineage decision during embryonic development is another example where the embryos of different mammals clearly vary between species, as recently emphasized by Rossant (2011).

Rabbit blastocysts can be exactly staged in living embryos in vivo and in vitro and are amenable to experimentation under standard culture conditions (Halacheva et al. 2011). Gene expression profiling of stage 0 to 3 blastocysts (Viebahn et al. 2002, Idkowiak et al. 2004, Ramin et al. 2010) and cell-lineage-specific molecular phenotyping (Navarrete Santos et al. 2008, Thieme et al. 2012a) have begun to emerge and will gradually generate a broad spectrum of molecular tools for this species.

\section{Feto-placental interactions and placental function and imaging}

Compared with other mammals, the rabbit blastocyst attaches to the uterine epithelium late in embryogenesis.
Implantation starts at day 6 plus $18 \mathrm{~h}$; definitive mesometrial chorioallantoid placentation occurs at day 8 p.c. (Denker 1977). Peri-implantation embryomaternal dialog depends on timely controlled mutual temporal and local signals. When interspecies comparisons are made, the expression of proprotein convertase 5/6 (PC 5/6), for example, required for uterine remodeling both in decidualizing cells and uterine epithelium in women and the rabbit, is of importance, since in mice PC 5/6 is only involved in decidualization, suggesting that the rabbit may be a very appropriate model to decipher molecular events during implantation (Nicholls et al. 2011).

The rabbit placenta develops as a discoid, hemochorial placenta such as that of the human and rodents (Duval 1889). Its hemodichorial structure (two cellular layers of chorion between the maternal and the fetal blood) is closer to that of the human in the last trimester (hemomonochorial) than the placenta of rodents (hemotrichorial). It shares with the rodents a labyrinth

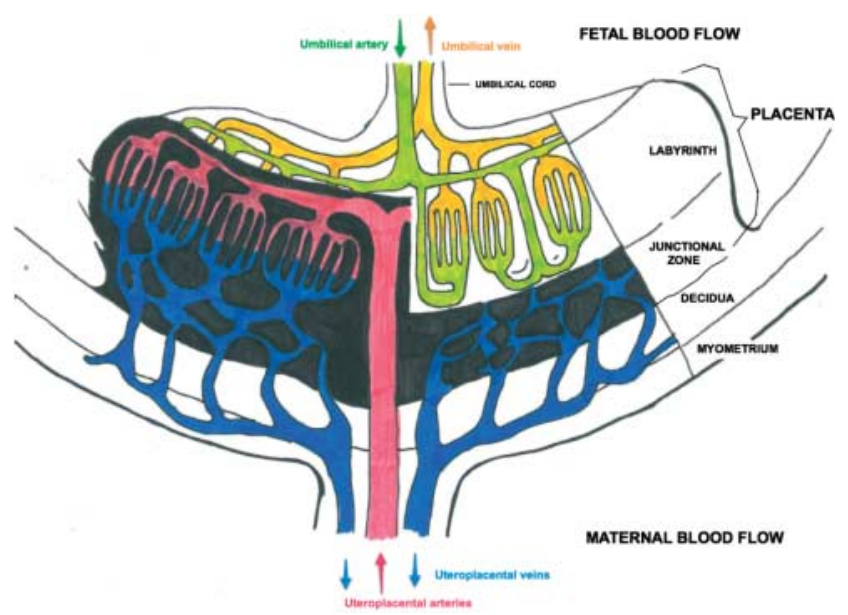

Figure 2 Schematic representation of the maternal and fetal blood flow in the rabbit placenta. Fetal blood reaches the placenta through two umbilical arteries that join the chorionic plaque. These arteries subsequently branch off and form a capillary network within the labyrinth that flow from the chorionic plaque toward the decidua. A venous network brings back the oxygenated blood to the chorionic plaque and umbilical cord. In contrast to fetal blood that remains within the blood vessels, the maternal blood flows within maternal vascular spaces, along trophoblastic columns from the chorial to the basal plaque. This counter-flow between maternal and fetal blood flow optimizes feto-maternal exchanges. 
(exchange region) as opposed to the microvillous chamber in humans (Enders \& Blankenship 1999, Foote \& Carney 2000; Fig. 2). As in primates, placental growth is most rapid in the first half of pregnancy, whereas fetal weight gain occurs in the second half due to a large increase in feto-maternal exchanges, mostly due to increased convolution of the exchange surface (McArdle et al. 2009).

Hemodynamic changes occurring during pregnancy are comparable with the human, with an important increase in maternal blood pressure throughout gestation. The placental giant cells, which originate from the trophoblast and which are present in the rabbit placenta from day 10 p.c., but not in the human placenta, are involved in the remodeling of the spiral arteries (Larsen 1962) replacing the endothelial cells, as in the invasive trophoblast in the human and as demonstrated in rodents. Moreover, a structural correlation between the expression of genes involved in the placental renin-angiotensin system and hemodynamic changes, observed by stereological approaches, underline the importance of the rabbit as a pertinent model for the study of pathologies that affect maternal blood pressure or placental perfusion during pregnancy (McArdle et al. 2009, 2010).

The relative large size of the rabbit compared with other laboratory animals makes it possible to monitor fetal and placental growth using conventional ultrasound equipment (Chavatte-Palmer et al. 2008, Polisca et al. 2010). Uterine artery ligations have been used to induce intra-uterine growth retardation (IUGR) and to evaluate modifications in blood flow using standard
Doppler ultrasound technology (Eixarch et al. 2009, 2011). 3D Power Doppler, which enables the quantification of blood flow within the human and sheep placenta (Morel et al. 2010), is also able to detect variation in vascularization within the rabbit placenta (Lecarpentier E, Morel O, Tarrade A, Dahirel M, Bonneau M, Gayat E, Evai-Brion D, Chavatte-Palmer P \& Tsatsaris $\mathrm{V}$, unpublished observations; Fig. 3).

\section{The rabbit as a tool for investigating hormonal regulation of the embryo-maternal dialog and the effects of maternal metabolic disorders on offspring development and health}

Within the Developmental Origins of Health and Disease concept (Barker 1998), a focus is increasingly laid on the periconceptional and feto-placental periods. The periconceptional period is particularly sensitive to metabolic disruption with long-term impacts on pre- and postnatal development and adult health (Kwong et al. 2000, Watkins et al. 2008a, 2008b, 2010). Endocrine and metabolic circuits characterize embryo-maternal interactions in these pregnancy stages, and confounders have been described, with most attention recently being paid to endocrine disrupters (cf. Fowler et al. 2012) and prevalent metabolic diseases such as diabetes mellitus and adiposity. Adipokines, a subset of cytokines derived from adipose tissue, affect metabolism and obesity particularly, as also fertility in women (Mitchell et al. 2005). Plasma levels are known to be decreased in patients suffering from type II diabetes and obesity.
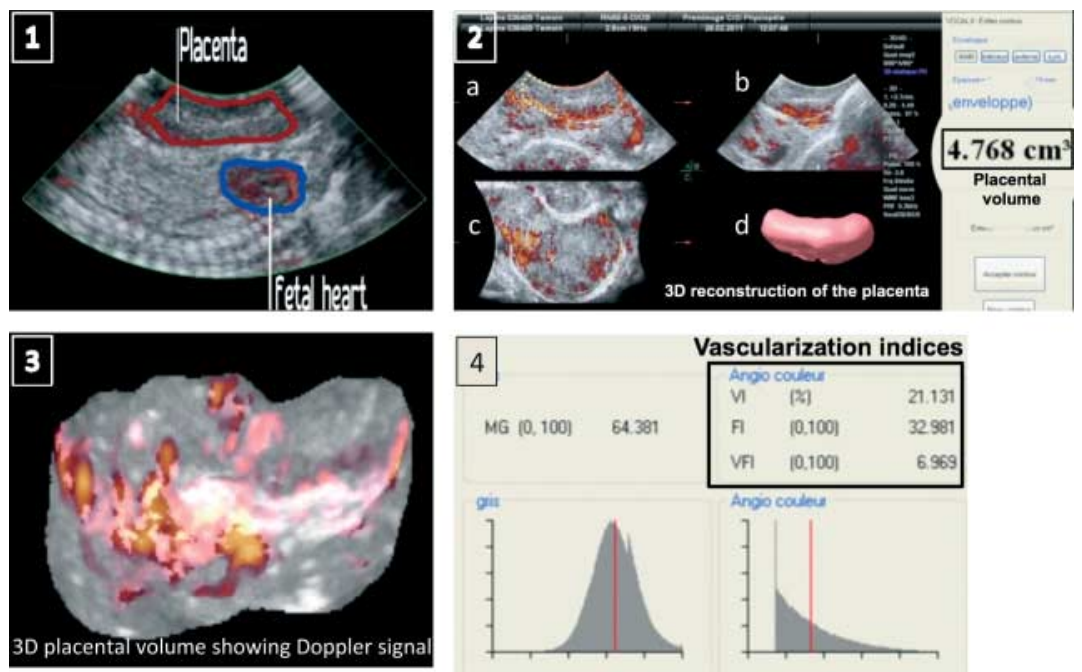

Figure 3 Photograph of 3D ultrasound of the placenta. Successive steps of quantitative 3D Doppler acquisition of the rabbit placenta, using a Voluson E8 (GE Medical Systems) ultrasound machine with a transabdominal multifrequency probe (RNA 5-9 MHz) enabling automatic 3D volume and power Doppler acquisitions. The orange color on the ultrasound images indicates blood flow. (1) Localization of the placenta and fetal heart on a 2D, power Doppler image, for 3D automatic scanning. (2) Reconstruction by automatic rotation of the image $\left(15^{\circ}\right)$ and manual drawing of the volume, to get the total placental volume. In this image, a, b and c represent the placenta visualized from the 3-dimensional planes, whereas $d$ represents the complete volume. (3) 3D reconstruction showing internal blood flow (this can be turned around on the screen). (4) Computer-calculated vascular indices: vascularization index $(\mathrm{VI})$, flow index $(\mathrm{FI})$ and vascularization flow index $(\mathrm{VFI})$. These indices are correlated to the blood flow. 
Adiponectin, the receptors adipoR1 and adipoR2, and the adiponectin paralogues CTRP2 and CTRP7 are expressed in rabbit endometrium and in blastocysts with a specific expression pattern in the embryonic disc (Schmidt et al. 2008). Adiponectin impairs insulin sensitivity in humans and rodents (Cnop et al. 2003). In addition, activation of IRS1-associated PI3 kinase ameliorates insulin sensitivity by enhanced glucose uptake in myocytes (Kurth-Kraczek et al. 1999, Maeda et al. 2002). In rabbit blastocysts, the translocation of glucose transporter 4 (GLUT4) and glucose uptake are activated by adiponectin in vitro (Fischer et al. 2010).

A possible explanation for periconceptional programming is the plasticity of the limited number of embryonic cells at this early stage in ontogenesis, whose modified metabolism induced by the environment may result in a larger shift in postnatal phenotype than at later stages when cellular mass is greater (Fleming et al. 2012). Later on, feto-placental interactions have been shown to be essential for modulating early effects of the environment (Vaughan et al. 2012). Due to its advantages in terms of early embryo development and placental structure and function, the rabbit is a pertinent model to study the impact of maternal metabolic disorders on offspring development as shown below using three examples.

\section{Diabetes mellitus}

Embryo development has recently been investigated in rabbits in which a diabetes mellitus type 1 has been induced experimentally by treatment with alloxan (Ramin et al. 2010, Thieme et al. 2012a). Expression and signaling of insulin, IGFs and GLUTs had earlier been studied (Navarrete Santos et al. 2004a, 2004b, 2008). The rabbit blastocyst expresses most GLUT isoforms (GLUT1, 3, 4, 8), insulin receptor (IR), IGF1, IGF2, IGF1R, IGF2R, but not insulin itself. Insulin is exclusively delivered by maternal secretions to the preimplantation embryo. Classical IR signaling via MAP kinases and PI3 kinase was found. Noteworthy, insulin/IGF signaling has cell-lineage-specific adjustments: insulin stimulates Erk1/2 in embryoblast and trophoblast and Akt in trophoblast but not embryoblast, whereas IGF1 activates both kinases exclusively in the embryoblast. While IGF1 acts primarily as a mitogen, insulin induces mitogenic and metabolic effects.

In peripheral blood of experimentally induced diabetic rabbits, hypoinsulinemia and hyperglycemia are measurable $48 \mathrm{~h}$ after the destruction of pancreatic $\beta$-cells. Within the uterine lumen, insulin is no longer measurable and the glucose concentration is increased by a factor of 3 (Ramin et al. 2010). An increase of uterine and blastocyst IGF1 and IGF2 (Thieme et al. $2012 b$ ) in these females may partly compensate for the reduced insulin/IGF sensitivity. Maternal diabetes downregulates IR and IGF1R signaling, delays blastocyst development and gastrulation and increases apoptotic cell death in the embryonic disc. The 'double face' of IGFs - growth factor of the embryoblast (Kaye 1997, Markham \& Kaye 2003, Navarrete Santos et al. 2004a) and pro-apoptotic effects in bovine blastocysts (Velazquez et al. 2011) - needs further clarification to improve understanding of potential mechanism(s) of periconceptional programming and diabetogenous embryopathies.

Ovulation and blastocyst numbers were significantly reduced in experimentally induced diabetic rabbits, mirroring subfertility of diabetic women. Insulin induced Wnt3a, Wnt4 and the mesoderm-specific transcription factor Brachyury in a temporal- and stage-specific expression pattern in gastrulating blastocysts. If cultured in vitro, only blastocysts cultured with insulin reached the Wnt3a, Wnt4 and Brachyury expression levels of stage 2 in vivo blastocysts (Thieme et al. 2012a), indicating that insulin is required for early gastrulation and mesoderm formation in rabbit blastocysts. Further work is currently ongoing to analyze subsequent fetoplacental and post-natal development.

\section{Maternal dyslipidemia}

Because of its lipid metabolism which is close to that of humans, with high LDL-cholesterol, and its sensitivity to developing atherosclerosis, the rabbit has often been used to study lipid metabolism-related diseases. In terms of reproduction, it is therefore a particularly suitable model to study the fetal and placental effects of maternal high-fat and/or high-cholesterol diets. Work by Napoli et al. (2000) and Palinski et al. (2001) has confirmed, using the rabbit model, the importance of maternal hypercholesterolemia in predisposing offspring to atherosclerosis and the role of preventive maternal treatment. Maternal hypercholesterolemia is also associated with IUGR in rabbits (Montoudis et al. 1999) and affects placental transfer of fatty acids and GLUT expression in the placenta (Kevorkova et al. 2007, Marseille-Tremblay et al. 2007, Ethier-Chiasson et al. 2008). When the high-cholesterol diet is enriched with poly-unsaturated fatty acids and is administered to females prior to puberty, gene expression is altered in the female's embryos, which subsequently develop IUGR leading to overweight in adult offspring (Picone et al. 2011). The cellular and molecular mechanisms involved are currently being studied.

\section{Obesity}

Although the use of high-fat diets in rabbits has been reported to induce lipid metabolism disorders and obesity (Antic et al. 1999, Zhao et al. 2008, Zheng et al. 2009), this is not the case in all studies and diets supplemented with fats due to spontaneous reduction of food intake (Armitage et al. 2005, Picone et al. 2011). 
As a consequence, high-fat and high-carbohydrate diets have been designed to induce obesity. In a recent study, it was shown that maternal obesity induced fetal IUGR (as already observed in other species), but also that mammary gland differentiation in the dam was advanced, with abnormal accumulation of milk and secretory products as early as mid-gestation (Hue-Beauvais et al. 2011). These observations contrast with those made in mice where obesity impaired maternal mammary development (Flint et al. 2005). Mammary gland development and milk composition have been described extensively in the rabbit (Denamur 1963, Houdebine et al. 1985, Baranyi et al. 1995). An important aspect of rabbit lactation for biomedical research is that rabbit dams only suckle once a day, which greatly simplifies the study of neonatal milk intake and/or oral supplementation with drugs or components at the time of suckling.

\section{Conclusions}

There are clear advantages in the use of the rabbit. Embryo and feto-placental development are similar to the human, making the rabbit a particularly suitable model for the impact of embryo and fetal development on offspring and adult health. Significant insights into various aspects of reproduction have been gained already in this species due to 1) exact staging of early embryonic developmental and maternal pregnancy stages, 2) large-sized blastocysts amenable to micromanipulation, 3) cell-lineage-specific analyses, 4) gastrulation stages representative of mammalian development, and 5) placental morphology and function similar to the human.

More recently, functional genomic tools have also become available in this species (Duranthon et al. 2012). A deep coverage draft $(7 \times)$ sequence of the rabbit genome has been released (http:://www.broadinstitute. org/models/europeanrabbit/), whose annotation is in progress (http://www.ensembl.org/Oryctolagus_cuniculus/). Concomitantly, transcriptomic data have been published (http://www.ncbi.nlm.nih.gov/dbEST/ and http://www. ebi.ac.uk/ena/data/view). A microarray dedicated to the embryo, although limited in size, has successfully been used to analyze gene expression in the early embryo (Leandri et al. 2009) and effects of the embryo's environment (Picone et al. 2011). More recently, a larger array has been made commercially available (Agilent Technologies, Palo Alto, CA, USA). This array is in the course of improvement (more than 12000 genes) and is available for use in the context of developmental biology and periconceptional/fetal programming (Duranthon, personal communication). Moreover, ES cell isolation has been reported (Honda et al. 2008, Intawicha et al. 2009), while the production of chimera using these cells remains rare (Zakhartchenko et al. 2011) and no germinal chimera have been reported yet. However, isolation of iPS cells should help the development of functional genomics analyses in this species (Honda et al. 2010). Finally, the concomitant development of genome data together with new transgenesis strategies (Duranthon et al. 2012), notably the possibility to target specific genes by injection of zinc finger nucleases into embryo cytoplasm (Flisikowska et al. 2011), should promote the rabbit to its legitimate place among the standard models for developmental biology and reproductive pathologies.

\section{Declaration of interest}

The authors declare that there is no conflict of interest that could be perceived as prejudicing the impartiality of this review.

\section{Funding}

Research in the authors' laboratories is supported by German Research Council (DFG; NA 418/4-2, VI 151/8-1; A N Santos, B Fischer, C Viebahn), EU (FP7-REEF No212885, EpiHealth №278418, COST FA 0702 GEMINI, COST TD1101 RGB-Net; B Fischer, A N Santos, C Viebahn), German Academic Exchange Service (DAAD; Go8, MÖB, Vigoni, Canada; $B$ Fischer, A $N$ Santos) and the Roux Programme of the MLU Faculty of Medicine, Halle (A N Santos, B Fischer) for Bernd Fischer, Anne Navarrete Santos and Christoph Viebahn. Pascale Chavatte-Palmer and Véronique Duranthon's work on rabbits were and are currently supported by INRA PHASE Dept incitative action grant (2009, 2011), ANR PTFV (IMAPREG project 2008-2011), Fondation de l'Avenir (project ETO-587), Académie de Médecine grant (EVUPA 3D) Agence de la Biomédecine and ANR Programme de Recherche en Génomique et Biotechnologies végétales (2010-2012, projet Plurabbit).

\section{Acknowledgements}

The authors thank their colleagues (Anne Tarrade, Madia Charlier, Nathalie Daniel, Nathalie Peynot, Catherine Archilla, Valérie Berthelot, Valérie Hallé, Laurence Fortun-Lamothe, Cathy Hue-Beauvais, Vassilis Tsatsaris), students (Roselyne Brat, Ann-Gael Cordier, Charlotte Dupont, Sünje Fischer, Jacqueline Gürke, Emmanuelle Koch, Roger Léandri, Olivier Morel, Olivier Picone, Edouard Lecarpentier, Adriana Reis e Silva, Audrey Rolland, Maria Schindler, Stefanie Seyring, René Thieme), post-doctoral fellows (Barbara Panneau, Nicole Ramin), technicians (Michaela Kirstein, Franziska Knöfel, Sabine Schrötter (Halle), Michèle Dahirel, Marie-Christine Aubrière, Céleste LeBourhis, Michel Baratte, Nicolas Stadler, Etienne Aujean, INRA Jouy), Evelyn Axmann and Elisabeth George for their devoted work and support.

\section{References}

Adams CE 1960a Embryonic mortality induced experimentally in the rabbit. Nature 188 332-333. (doi:10.1038/188332a0) 
Adams CE $1960 b$ Prenatal mortality in the rabbit Oryctolagus cuniculus. Journal of Reproduction and Fertility $\mathbf{1}$ 36-44. (doi:10.1530/jrf.0. 0010036)

Adams CE 1962 Studies on prenatal mortality in the rabbit, Oryctolagus cuniculus: the effect of transferring varying numbers of eggs. Journal of Endocrinology 24 471-490. (doi:10.1677/joe.0.0240471)

Adams CE 1982 Egg transfer in the rabbit. In Mammalian Egg Transfer, pp 29-48. Boca Raton, FL: CRC Press.

Andrey P, Kieu K, Kress C, Lehmann G, Tirichine L, Liu Z, Biot E, Adenot PG, Hue-Beauvais C, Houba-Herin N et al. 2010 Statistical analysis of 3D images detects regular spatial distributions of centromeres and chromocenters in animal and plant nuclei. PLoS Computational Biology 6 e1000853. (doi:10.1371/journal.pcbi.1000853)

Antic V, Tempini A \& Montani JP 1999 Serial changes in cardiovascular and renal function of rabbits ingesting a high-fat, high-calorie diet. American Journal of Hypertension 12 826-829. (doi:10.1016/S0895-7061(98) 00231-3)

Armitage JA, Taylor PD \& Poston L 2005 Experimental models of developmental programming: consequences of exposure to an energy rich diet during development. Journal of Physiology 565 3-8. (doi:10. 1113/jphysiol.2004.079756)

Baranyi M, Brignon G, Anglade P \& Ribadeau-Dumas B 1995 New data on the proteins of rabbit (Oryctolagus cuniculus) milk. Comparative Biochemistry and Physiology. Part B, Biochemistry and Molecular Biology 111 407-415. (doi:10.1016/0305-0491(95)00008-V)

Barker DJP 1998 Mothers, Babies and Health in Later Life. Edinburgh: Churchill Livingstone.

Beddington RS \& Robertson EJ 1999 Axis development and early asymmetry in mammals. Cell 96 195-209. (doi:10.1016/S00928674(00)80560-7)

Beier HM 1968 Uteroglobin: a hormone-sensitive endometrial protein involved in blastocyst development. Biochimica et Biophysica Acta $\mathbf{1 6 0}$ 289-291.

Beier HM 2000 The discovery of uteroglobin and its significance for reproductive biology and endocrinology. Annals of the New York Academy of Sciences 923 9-24. (doi:10.1111/j.1749-6632.2000. tb05516.x)

Biggers JD, Bell JE \& Benos DJ 1988 Mammalian blastocyst: transport functions in a developing epithelium. American Journal of Physiology 255 C419-C432.

Brachet A 1913 Recherches sur le déterminisme héréditaire de l'oeuf des Mammifères. Développement 'in vitro' de jeunes vésicules blastodermiques de Lapin. Archives de Biologie 28 447-503.

Chavatte-Palmer $\mathbf{P}$, Laigre $\mathbf{P}$, Simonoff $E$, Chesne $\mathbf{P}$, Challah-Jacques $\mathbf{M}$ \& Renard JP 2008 In utero characterisation of fetal growth by ultrasound scanning in the rabbit. Theriogenology 69 859-869. (doi:10.1016/ j.theriogenology.2007.12.013)

Cnop M, Havel PJ, Utzschneider KM, Carr DB, Sinha MK, Boyko EJ, Retzlaff BM, Knopp RH, Brunzell JD \& Kahn SE 2003 Relationship of adiponectin to body fat distribution, insulin sensitivity and plasma lipoproteins: evidence for independent roles of age and sex. Diabetologia 46 459-469. (doi:10.1007/s00125-003-1074-z)

Denamur R 1963 Nucleic acids of the mammary gland during gestation and lactation in the rabbit. Comptes Rendus Hebdomadaires des séances de l'Académie des Sciences 256 4748-4750.

Denker HW 1977 Implantation. The role of proteinases, and blockage of implantation by proteinase inhibitors. Advances in Anatomy, Embryology, and Cell Biology 53 3-123.

Denker HW \& Gerdes HJ 1979 The dynamic structure of rabbit blastocyst coverings. I. Transformation during regular preimplantation development. Anatomica Embryologica 157 15-34. (doi:10.1007/BF00315639)

Duranthon V, Beaujean N, Brunner M, Odening KE, Santos AN, Kacskovics I, Hiripi L, Weinstein EJ \& Bosze Z 2012 On the emerging role of rabbit as human disease model and the instrumental role of novel transgenic tools. Transgenic Research [in press]. (doi:10.1007/ s11248-012-9599-x)

Duval M 1889 Le placenta des rongeurs: Le placenta du lapin. Journal de L'Anatomie et de la Physiologie Normales et Pathologiques de L'Homme et des Animaux 25 573-627.

Eixarch E, Figueras F, Hernandez-Andrade E, Crispi F, Nadal A, Torre I, Oliveira S \& Gratacos E 2009 An experimental model of fetal growth restriction based on selective ligature of uteroplacental vessels in the pregnant rabbit. Fetal Diagnosis and Therapy 26 203-211. (doi:10.1159/ 000264063)

Eixarch E, Hernandez-Andrade E, Crispi F, Illa M, Torre I, Figueras F \& Gratacos E 2011 Impact on fetal mortality and cardiovascular Doppler of selective ligature of uteroplacental vessels compared with undernutrition in a rabbit model of intrauterine growth restriction. Placenta 32 304-309. (doi:10.1016/j.placenta.2011.01.014)

Enders AC \& Blankenship TN 1999 Comparative placental structure. Advanced Drug Delivery Reviews 38 3-15. (doi:10.1016/S0169409X(99)00003-4)

Ethier-Chiasson M, Forest JC, Giguere Y, Masse A, Marseille-Tremblay C, Levy E \& Lafond J 2008 Modulation of placental protein expression of OLR1: implication in pregnancy-related disorders or pathologies. Reproduction 136 491-502. (doi:10.1530/REP-08-0082)

Fischer B \& Meuser-Odenkirchen G 1988 A 2 year follow-up of effects of biotechniques on reproduction in the domestic rabbit, Oryctolagus cuniculus. Laboratory Animals 22 5-15. (doi:10.1258/002367788 780746629)

Fischer B, Winterhager E \& Busch LC 1986 Transformation of endometrium and fertility in late stages of pseudopregnancy in the rabbit. Journal of Reproduction and Fertility 78 529-540. (doi:10.1530/jrf.0.0780529)

Fischer B, Mootz U, Denker HW, Lambertz M \& Beier HM 1991 The dynamic structure of rabbit blastocyst coverings. III. Transformation of coverings under non-physiological developmental conditions. Anatomica Embryologica 183 17-27. (doi:10.1007/BF00185831)

Fischer S, Santos AN, Thieme R, Ramin N \& Fischer B 2010 Adiponectin stimulates glucose uptake in rabbit blastocysts. Biology of Reproduction 83 859-865. (doi:10.1095/biolreprod.110.084665)

Fleming TP, Velazquez MA, Eckert JJ, Lucas ES \& Watkins AJ 2012 Nutrition of females during the peri-conceptional period and effects on foetal programming and health of offspring. Animal Reproduction Science 130 193-197. (doi:10.1016/j.anireprosci.2012.01.015)

Flint DJ, Travers MT, Barber MC, Binart N \& Kelly PA 2005 Diet-induced obesity impairs mammary development and lactogenesis in murine mammary gland. American Journal of Physiology. Endocrinology and Metabolism 288 E1179-E1187. (doi:10.1152/ajpendo.00433.2004)

Flisikowska T, Thorey IS, Offner S, Ros F, Lifke V, Zeitler B, Rottmann O, Vincent A, Zhang L, Jenkins S et al. 2011 Efficient immunoglobulin gene disruption and targeted replacement in rabbit using zinc finger nucleases. PLoS ONE 6 e21045. (doi:10.1371/journal.pone.0021045)

Foote RH \& Carney EW 2000 The rabbit as a model for reproductive and developmental toxicity studies. Reproductive Toxicology 14 477-493. (doi:10.1016/S0890-6238(00)00101-5)

Fowler PA, Bellingham M, Sinclair KD, Evans NP, Pocar P, Fischer B, Schaedlich K, Schmidt JS, Amezaga MR, Bhattacharya S et al. 2012 Impact of endocrine-disrupting compounds (EDCs) on female reproductive health. Molecular and Cellular Endocrinology 355 231-239. (doi:10. 1016/j.mce.2011.10.021)

Gottschewki GHM \& Zimmermann W 1973 Die Embryonalentwicklung des Hauskaninchens Normogenese und Teratogenese. Hannover: Verlag M.\& H. Schaper.

Graur D, Duret L \& Gouy M 1996 Phylogenetic position of the order Lagomorpha (rabbits, hares and allies). Nature 379 333-335. (doi:10.1038/379333a0)

Halacheva V, Fuchs M, Donitz J, Reupke T, Puschel B \& Viebahn C 2011 Planar cell movements and oriented cell division during early primitive streak formation in the mammalian embryo. Developmental Dynamics 240 1905-1916. (doi:10.1002/dvdy.22687)

Hamburger V \& Hamilton HL 1992 A series of normal stages in the development of the chick embryo. 1951. Developmental Dynamics 195 231-272. (doi:10.1002/aja.1001950404)

Harper MJ 1961 The time of ovulation in the rabbit following the injection of luteinizing hormone. Journal of Endocrinology 22 147-152. (doi:10. 1677/joe.0.0220147)

Hay MF 1964 Effects of thalidomide on pregnancy in the rabbit. Journal of Reproduction and Fertility 8 59-76. (doi:10.1530/jrf.0.0080059)

Honda A, Hirose M, Inoue K, Ogonuki N, Miki H, Shimozawa N, Hatori M, Shimizu N, Murata T, Katayama K et al. 2008 Stable embryonic stem cell lines in rabbits: potential small animal models for human research. Reproductive BioMedicine Online 17 706-715. (doi:10.1016/S14726483(10)60320-3) 
Honda A, Hirose M, Hatori M, Matoba S, Miyoshi H, Inoue K \& Ogura A 2010 Generation of induced pluripotent stem cells in rabbits: potential experimental models for human regenerative medicine. Journal of Biological Chemistry 285 31362-31369. (doi:10.1074/jbc.M110.150540)

Houdebine LM, Djiane J, Dusanter-Fourt I, Martel P, Kelly PA, Devinoy E \& Servely JL 1985 Hormonal action controlling mammary activity. Journal of Dairy Science 68 489-500. (doi:10.3168/jds.S00220302(85)80848-1)

Hue-Beauvais C, Chavatte-Palmer P, Aujean E, Dahirel M, Laigre P, Pechoux C, Bouet S, Devinoy E \& Charlier M 2011 An obesogenic diet started before puberty leads to abnormal mammary gland development during pregnancy in the rabbit. Developmental Dynamics 240 347-356. (doi:10.1002/dvdy.22536)

Idkowiak J, Weisheit G, Plitzner J \& Viebahn C 2004 Hypoblast controls mesoderm generation and axial patterning in the gastrulating rabbit embryo. Development Genes and Evolution 214 591-605. (doi:10.1007/ s00427-004-0436-y)

Intawicha P, Ou YW, Lo NW, Zhang SC, Chen YZ, Lin TA, Su HL, Guu HF, Chen MJ, Lee KH et al. 2009 Characterization of embryonic stem cell lines derived from New Zealand white rabbit embryos. Cloning and Stem Cells 11 27-38. (doi:10.1089/clo.2008.0040)

Jung T \& Fischer B 1988 Correlation between diameter and DNA or protein synthetic activity in rabbit blastocysts. Biology of Reproduction 39 1111-1116. (doi:10.1095/biolreprod39.5.1111)

Kaye PL 1997 Preimplantation growth factor physiology. Reviews of Reproduction 2 121-127. (doi:10.1530/ror.0.0020121)

Kevorkova O, Ethier-Chiasson M \& Lafond J 2007 Differential expression of glucose transporters in rabbit placenta: effect of hypercholesterolemia in dams. Biology of Reproduction 76 487-495. (doi:10.1095/biolreprod. 106.055285)

Kurth-Kraczek EJ, Hirshman MF, Goodyear LJ \& Winder WW 1999 5'AMPactivated protein kinase activation causes GLUT4 translocation in skeletal muscle. Diabetes 48 1667-1671. (doi:10.2337/diabetes.48.8. 1667)

Kwong WY, Wild AE, Roberts P, Willis AC \& Fleming TP 2000 Maternal undernutrition during the preimplantation period of rat development causes blastocyst abnormalities and programming of postnatal hypertension. Development 127 4195-4202.

Larsen JF 1962 Electron microscopy of the chorioallantoic placenta of the rabbit: 1 . The placental labyrinth and the multinucleated giant cells of the intermediate zone. Journal of Ultrastructure Research 7 535-549. (doi:10.1016/S0022-5320(62)90044-8)

Leandri RD, Archilla C, Bui LC, Peynot N, Liu Z, Cabau C, Chastellier A, Renard JP \& Duranthon V 2009 Revealing the dynamics of gene expression during embryonic genome activation and first differentiation in the rabbit embryo with a dedicated array screening. Physiological Genomics 36 98-113. (doi:10.1152/physiolgenomics. 90310.2008)

Lenz W 1988 A short history of thalidomide embryopathy. Teratology 38 203-215. (doi:10.1002/tera.1420380303)

Maeda N, Shimomura I, Kishida K, Nishizawa H, Matsuda M, Nagaretani H, Furuyama N, Kondo H, Takahashi M, Arita $Y$ et al. 2002 Diet-induced insulin resistance in mice lacking adiponectin/ACRP30. Nature Medicine 8 731-737. (doi:10.1038/nm724)

Manes C 1973 The participation of embryonic genome during early cleavage in the rabbit. Developmental Biology 32 453-459. (doi:10. 1016/0012-1606(73)90254-6)

Markham KE \& Kaye PL 2003 Growth hormone, insulin-like growth factor I and cell proliferation in the mouse blastocyst. Reproduction 125 327-336. (doi:10.1530/rep.0.1250327)

Marseille-Tremblay C, Gravel A, Lafond J \& Mounier C 2007 Effect of an enriched cholesterol diet during gestation on fatty acid synthase, HMGCoA reductase and SREBP-1/2 expressions in rabbits. Life Sciences $\mathbf{8 1}$ 772-778. (doi:10.1016/j.Ifs.2007.07.016)

McArdle AM, Denton KM, Maduwegedera D, Moritz K, Flower RL \& Roberts CT 2009 Ontogeny of placental structural development and expression of the renin-angiotensin system and $11 \beta-\mathrm{HSD} 2$ genes in the rabbit. Placenta 30 590-598. (doi:10.1016/j.placenta.2009.04.006)

McArdle AM, Roberts CT, Maduwegedera D, Flower RL \& Denton KM 2010 Chronic maternal hypertension characterized by renal dysfunction is associated with reduced placental blood flow during late gestation in rabbits. American Journal of Physiology. Regulatory, Integrative and Comparative Physiology 298 R1043-R1049. (doi:10.1152/ajpregu. 00202.2009)

Mitchell M, Armstrong DT, Robker RL \& Norman RJ 2005 Adipokines: implications for female fertility and obesity. Reproduction 130 583-597. (doi:10.1530/rep.1.00521)

Montoudis A, Simoneau L, Brissette L, Forest JC, Savard R \& Lafond J 1999 Impact of a cholesterol enriched diet on maternal and fetal plasma lipids and fetal deposition in pregnant rabbits. Life Sciences 64 2439-2450. (doi:10.1016/S0024-3205(99)00201-5)

Morel O, Pachy F, Chavatte-Palmer P, Bonneau M, Gayat E, Laigre P, Evain-Brion D \& Tsatsaris V 2010 Correlation between uteroplacental three-dimensional power Doppler indices and true uterine blood flow: evaluation in a pregnant sheep model. Ultrasound in Obstetrics and Gynecology 36 635-640. (doi:10.1002/uog.7741)

Napoli C, Witztum JL, Calara F, de Nigris F \& Palinski W 2000 Maternal hypercholesterolemia enhances atherogenesis in normocholesterolemic rabbits, which is inhibited by antioxidant or lipid-lowering intervention during pregnancy: an experimental model of atherogenic mechanisms in human fetuses. Circulation Research 87 946-952. (doi:10.1161/01.RES. 87.10.946)

Navarrete Santos A, Tonack S, Kirstein M, Kietz S \& Fischer B 2004a Two insulin-responsive glucose transporter isoforms and the insulin receptor are developmentally expressed in rabbit preimplantation embryos. Reproduction 128 503-516. (doi:10.1530/rep.1.00203)

Navarrete Santos A, Tonack S, Kirstein M, Pantaleon M, Kaye P \& Fischer B $2004 \mathrm{~b}$ Insulin acts via mitogen-activated protein kinase phosphorylation in rabbit blastocysts. Reproduction 128 517-526. (doi:10.1530/rep.1. 00204)

Navarrete Santos A, Ramin N, Tonack S \& Fischer B 2008 Cell lineagespecific signaling of insulin and insulin-like growth factor $I$ in rabbit blastocysts. Endocrinology 149 515-524. (doi:10.1210/en.2007-0821)

Nicholls PK, Sun Z, Heng S, Li Y, Wang J \& Nie G 2011 Embryo implantation is closely associated with dynamic expression of proprotein convertase $5 / 6$ in the rabbit uterus. Reproductive Biology and Endocrinology 9 43. (doi:10.1186/1477-7827-9-43)

Okamoto I, Patrat C, Thepot D, Peynot N, Fauque P, Daniel N, Diabangouaya P, Wolf JP, Renard JP, Duranthon V et al. 2011 Eutherian mammals use diverse strategies to initiate X-chromosome inactivation during development. Nature 472 370-374. (doi:10.1038/nature09872)

Pacheco-Trigon S, Hennequet-Antier C, Oudin JF, Piumi F, Renard JP \& Duranthon V 2002 Molecular characterization of genomic activities at the onset of zygotic transcription in mammals. Biology of Reproduction 67 1907-1918. (doi:10.1095/biolreprod67.6.1907)

Palinski W, D'Armiento FP, Witztum JL, de Nigris F, Casanada F, Condorelli M, Silvestre M \& Napoli C 2001 Maternal hypercholesterolemia and treatment during pregnancy influence the long-term progression of atherosclerosis in offspring of rabbits. Circulation Research 89 991-996. (doi:10.1161/hh2301.099646)

Picone O, Laigre P, Fortun-Lamothe L, Archilla C, Peynot N, Ponter AA, Berthelot V, Cordier AG, Duranthon V \& Chavatte-Palmer P 2011 Hyperlipidic hypercholesterolemic diet in prepubertal rabbits affects gene expression in the embryo, restricts fetal growth and increases offspring susceptibility to obesity. Theriogenology 75 287-299. (doi:10. 1016/j.theriogenology.2010.08.015)

Polisca A, Scotti L, Orlandi R, Brecchia G \& Boiti C 2010 Doppler evaluation of maternal and fetal vessels during normal gestation in rabbits. Theriogenology 73 358-366. (doi:10.1016/j.theriogenology. 2009.09.019)

Ramin N, Thieme R, Fischer S, Schindler M, Schmidt T, Fischer B \& Navarrete Santos A 2010 Maternal diabetes impairs gastrulation and insulin and IGF-I receptor expression in rabbit blastocysts. Endocrinology 151 4158-4167. (doi:10.1210/en.2010-0187)

Reis Silva AR, Adenot P, Daniel N, Archilla C, Peynot N, Lucci CM, Beaujean N \& Duranthon V 2011 Dynamics of DNA methylation levels in maternal and paternal rabbit genomes after fertilization. Epigenetics 6 987-993. (doi:10.4161/epi.6.8.16073)

Reis Silva AR, Bruno C, Fleurot R, Daniel N, Archilla C, Peynot N, Lucci CM \& Beaujean N 2012 Alteration of DNA demethylation dynamics by in vitro culture conditions in rabbit preimplantation embryos. Epigenetics 7 440-446. (doi:10.4161/epi.19563) 
Rossant J 2011 Developmental biology: a mouse is not a cow. Nature $\mathbf{4 7 1}$ 457-458. (doi:10.1038/471457a)

Schafer-Haas A \& Viebahn C 2000 The term cell epitope PG-2 is expressed in primordial germ cells and in hypoblast cells of the gastrulating rabbit embryo. Anatomica Embryologica 202 13-23. (doi:10.1007) PL00008240)

Schmidt T, Fischer S, Tsikolia N, Navarrete Santos A, Rohrbach S, Ramin N, Thieme R \& Fischer B 2008 Expression of adipokines in preimplantation rabbit and mice embryos. Histochemistry and Cell Biology 129 817-825. (doi:10.1007/s00418-008-0409-8)

Schumacher H, Blake DA, Gurian JM \& Gillette JR 1968 A comparison of the teratogenic activity of thalidomide in rabbits and rats. Journal of Pharmacology and Experimental Therapeutics 160 189-200.

Somers GS 1962 Thalidomide and congenital abnormalities. Lancet 1 912-913. (doi:10.1016/S0140-6736(62)91943-8)

Telford NA, Watson AJ \& Schultz GA 1990 Transition from maternal to embryonic control in early mammalian development: a comparison of several species. Molecular Reproduction and Development 26 90-100. (doi:10.1002/mrd.1080260113)

Thieme R, Ramin N, Fischer S, Puschel B, Fischer B \& Santos AN 2012a Gastrulation in rabbit blastocysts depends on insulin and insulin-likegrowth-factor 1. Molecular and Cellular Endocrinology 348 112-119. (doi:10.1016/j.mce.2011.07.044)

Thieme R, Schindler M, Ramin N, Fischer S, Mühleck B, Fischer B \& Navarrete Santos A 2012b Insulin growth factor adjustment in preimplantation rabbit blastocysts and uterine tissues in response to maternal type 1 diabetes. Molecular and Cellular Endocrinology 358 96-103. (doi:10.1016/j.mce.2012.03.007)

Tscheudschilsuren G, Kuchenhoff A, Klonisch T, Tetens F \& Fischer B 1999 Induction of arylhydrocarbon receptor expression in embryoblast cells of rabbit preimplantation blastocysts upon degeneration of Rauber's polar trophoblast. Toxicology and Applied Pharmacology 157 125-133. (doi:10.1006/taap.1999.8667)

Vaughan OR, Sferruzzi-Perri AN, Coan PM \& Fowden AL 2012 Environmental regulation of placental phenotype: implications for fetal growth. Reproduction, Fertility, and Development 24 80-96. (doi:10. 1071/RD11909)

Velazquez MA, Hermann D, Kues WA \& Niemann H 2011 Increased apoptosis in bovine blastocysts exposed to high levels of IGF1 is not associated with downregulation of the IGF1 receptor. Reproduction 141 91-103. (doi:10.1530/REP-10-0336)

Viebahn C 1999 The anterior margin of the mammalian gastrula: comparative and phylogenetic aspects of its role in axis formation and head induction. Current Topics in Developmental Biology 46 63-103.

Viebahn C 2001 Hensen's node. Genesis 29 96-103. (doi:10.1002/1526968X(200102)29:2 < 96::AID-GENE1010>3.0.CO;2-H)
Viebahn C 2004 Gastrulation in the rabbit. In Gastrulations, pp 263-274. Cold Spring Harbor, NY: Cold Spring Harbor Laboratory Press.

Viebahn C, Mayer B \& Hrabe de Angelis M 1995 Signs of the principle body axes prior to primitive streak formation in the rabbit embryo. Anatomica Embryologica 192 159-169. (doi:10.1007/BF00186004)

Viebahn C, Stortz C, Mitchell SA \& Blum M 2002 Low proliferative and high migratory activity in the area of Brachyury expressing mesoderm progenitor cells in the gastrulating rabbit embryo. Development 129 2355-2365.

Watkins AJ, Ursell E, Panton R, Papenbrock T, Hollis L, Cunningham C, Wilkins A, Perry VH, Sheth B, Kwong WY et al. 2008a Adaptive responses by mouse early embryos to maternal diet protect fetal growth but predispose to adult onset disease. Biology of Reproduction $\mathbf{7 8}$ 299-306. (doi:10.1095/biolreprod.107.064220)

Watkins AJ, Wilkins A, Cunningham C, Perry VH, Seet MJ, Osmond C, Eckert JJ, Torrens C, Cagampang FR, Cleal J et al. 2008b Low protein diet fed exclusively during mouse oocyte maturation leads to behavioural and cardiovascular abnormalities in offspring. Journal of Physiology $\mathbf{5 8 6}$ 2231-2244. (doi:10.1113/jphysiol.2007.149229)

Watkins AJ, Lucas ES, Torrens C, Cleal JK, Green L, Osmond C, Eckert JJ, Gray WP, Hanson MA \& Fleming TP 2010 Maternal low-protein diet during mouse pre-implantation development induces vascular dysfunction and altered renin-angiotensin-system homeostasis in the offspring. British Journal of Nutrition 103 1762-1770. (doi:10.1017/S0007114509993783)

Williams BS \& Biggers JD 1990 Polar trophoblast (Rauber's layer) of the rabbit blastocyst. Anatomical Record 227 211-222. (doi:10.1002/ar. 1092270210)

Zakhartchenko V, Flisikowska T, Li S, Richter T, Wieland H, Durkovic M, Rottmann O, Kessler B, Gungor T, Brem G et al. 2011 Cell-mediated transgenesis in rabbits: chimeric and nuclear transfer animals. Biology of Reproduction 84 229-237. (doi:10.1095/biolreprod.110.087098)

Zhao S, Chu Y, Zhang C, Lin Y, Xu K, Yang P, Fan J \& Liu E 2008 Dietinduced central obesity and insulin resistance in rabbits. Journal of Animal Physiology and Animal Nutrition 92 105-111. (doi:10.1111/ j.1439-0396.2007.00723.x)

Zheng H, Zhang C, Yang W, Wang Y, Lin Y, Yang P, Yu Q, Fan J \& Liu E 2009 Fat and cholesterol diet induced lipid metabolic disorders and insulin resistance in rabbit. Experimental and Clinical Endocrinology \& Diabetes 117 400-405. (doi:10.1055/s-0028-1102918)

Received 13 March 2012

First decision 2 May 2012

Revised manuscript received 7 May 2012

Accepted 10 May 2012 